\title{
Electromyographic Study of the Masseter Muscle after Lower Third Molar Surgery
}

\author{
Estudio Electromiográfico del Músculo Masetero tras Cirugía de Tercer Molar Inferior
}

\author{
"Tarley Eloy Pessoa de Barros; "Gabriel Denser Campolongo; \\ "Reginaldo Perilo de Oliveira; ${ }^{* *}$ Nilton Alves \& ${ }^{* * *}$ Reinaldo José de Oliveira
}

\begin{abstract}
BARROS, T. E. P.; CAMPOLONGO, G. D.; OLIVEIRA, N.; ALVES, N. \& OLIVEIRA, R. J. Electromyographic study of the masseter muscle after lower third molar surgery. Int. J. Morphol., 29(1):304-309, 2011.

SUMMARY: Third molar extraction surgery is one of the most frequently performed procedures in the areas of buccal-maxillofacial traumatology and surgery. The post-surgery evolution was evaluated based on the clinical evidence obtained so far. The objective of this study was to analyze the post-surgery clinical evolution of the masseter muscle by means of surface electromyography, to evaluate muscle activity. Four analyses were performed: one pre-surgery, to register the normal activity, and three in post-surgery: on the $7^{\text {th }}, 14^{\text {th }}$ and $21^{\text {st }}$ postoperative days, in a sample of 30 patients. On the $21^{\text {st }}$ day, there was near normal recovery of the electrical signal of the masseter in women, but in men this activity did not reach normal levels. Surface electromyography is a safe and reliable tool for postsurgery evolution control of masseter function.
\end{abstract}

KEY WORDS: Electromyography; Masseter muscle; Third molar; Electrodes.

\section{INTRODUCTION}

Surgical removal of the third molar (the "wisdom tooth") has become routine in dental clinics. Surgery is indicated in several situations, including orthodontic factors, poor positioning of the teeth and other factors, pericoronitis being the most frequent cause for extraction of third molar teeth. Third molars, when impacted in the bone, can cause inconvenience and are harmful to oral health, which justifies their extraction (Goldberg et al., 1985; Mercier \& Precious, 1992; Cerqueira et al., 2004). However, the procedure can result in considerable pain, swelling, trismus (the most common complication), alveolitis, infection, bleeding and dentoalveolar fractures (Mercier \& Precious; Chiapasco et al., 1993; Garcia-Garcia et al., 1997; Norholt et al., 1998), paralysis of the lower alveolar nerve (paresthesia), which occurs in 13.4\% of cases (Brann et al., 1999) and reduced ability to open the mouth, which occurs in $31 \%$ of cases (Berge, 1996) and decreases with time (Suarez-Cunqueiro et al., 2003). Contributing factors to these sequelae include those related to the inflammatory process initiated by the surgical procedure itself (Goldberg et al.). In the postoperative evaluation of masseter muscle function, clinical observation is predominant, but is subject to difficult and variable interpretations (Solberg, 1986).

Electromyography allows muscle function to be assessed by analyzing the electrical signal produced during muscle contraction. The electrical potential of the muscles can be recorded in normal, healthy conditions or following surgical procedures, enabling damage to the muscle function, and in particular, the time required to complete function recovery (Goldstein, 2000) to be understood, interpreted, and recognized. An increased electromyographic signal is indicative of craniomandibular dysfunction, registering the hyperactivity of the masticatory muscles in the resting position and the decrease in activity during maximal voluntary contraction (Dahlström, 1989). Electromyography can also help the surgeon evaluate whether physical therapy is needed in each case, in order to accelerate a return to

\footnotetext{
* Institute of Orthopedics and Traumatology, Hospital das Clínicas, Faculdade de Medicina da Universidade de São Paulo, São Paulo, Brazil.

** Unidad de Anatomía Normal, Facultad de Ciencias de la Salud, Universidad de Talca, Talca, Chile.

**** Faculdade de Odontologia, UNIBAN - Universidade Bandeirante, São Paulo, Brasil.
} 
normality (Goldstein). Electromyography is a noninvasive procedure which is easy to use, fast and painless, which undoubtedly promotes cooperation by the patient. This test therefore provides the healthcare professional with a safe and objective analysis, through the monitoring and data logging of the masticatory muscles.

\section{MATERIAL AND METHOD}

In our study 30 adult patients aged 30 years or under were evaluated, referred to the Institute of Orthopedics and Traumatology of the Hospital das Clínicas, Faculdade de Medicina da Universidade de São Paulo, Brazil, between January and December 2006, with indication of surgical removal of the mandibular third molar. All the patients were submitted to diagnostic exams consisting of clinical, physical and radiographic evaluations.

Electromiographic study: For the signal capture, a 4channel, 14-bit resolution, large array Miotool 400 surface electromyography device (Miotec, Porto Alegre, Brazil) was used, connected to the masseter through individual double pediatric Medi-Trace electrodes, with $\mathrm{Ag} / \mathrm{AgCl}$ (solid gel, hydrogel, adhesive and conductor) with a distance of $20 \mathrm{~mm}$ between poles. The data were interpreted using the Miography software, from Miotec.

The total examination time was 30 seconds, divided into alternating phases of five seconds each, in which there was voluntary relaxation of the masseter muscle, followed by a five-second period when the patient exerted the maximum possible contraction of the masseter muscle by biting on a piece of cotton: from 0 to 5 seconds: relaxation; from 5 to 10 seconds: contraction; from 10 to 15 seconds: relaxation; from 15 to 20 seconds: contraction; from 20 to 25 seconds: relaxation; from 25 to 30 seconds: contraction.

The gain was 200 times, applying a bandpass filter set between $20 \mathrm{~Hz}$ and $300 \mathrm{~Hz}$ to eliminate other external influences. The reading was performed by a physiotherapist and recorded on a specific form for the files.

Electrodes: After swabbing the skin with $70 \%$ alcohol, the electrodes were placed according to the following protocol: first, the skin was prepared with a thick sponge, to remove fat and loose skin; then an earth electrode was placed on the region of the medial epicondyle of the humerus; Next, a recording electrode (double) was placed on the upper portion of the masseter muscle to be studied (right or left); and another was fitted in the region of insertion.
Surface electromyography: The patient sat with the back fully supported on the chair, in the Frankfort plane parallel to the ground, eyes open, feet flat on the floor and arms resting on the lower limbs. The electromyographic signal was captured in four evaluations: First evaluation: between the $6^{\text {th }}$ and $7^{\text {th }}$ preoperative days. Second evaluation: between the 6 th and 7 th postoperative days. Third evaluation: between the $13^{\text {th }}$ and $14^{\text {th }}$ postoperative days. Fourth evaluation: between the $20^{\text {th }}$ and $21^{\text {st }}$ days after surgery.

The results of muscle activity were analyzed and compared, to estimate the recovery period. Quantitative measurements of the root mean square (RMS) of the electrical activity of the masseter muscle, expressed in microvolts $(\mathrm{mV})$, obtained by surface electromyography, were recorded for each patient. The data were transferred to spreadsheets, identifying the patient's sex, the operated side, and the evaluation time (preoperative and days 7, 14 and 21 after surgery). The descriptive results were expressed in means, standard deviation, mean standard error, minimum and maximum values, and frequency (n).

Statistical analysis: Statistical analysis was performed using the Kolmogorov-Smirnov test (for normal distribution), Pearson's variation coefficient (for parametric distribution), the student $t$ test (independent samples with parametric distribution), the paired t test (dependent samples with parametric distribution and pairs of related samples with parametric distribution), Pearson's correlation test (for effectiveness of pairing between quadratic means), Chi-squared, analysis of variance (ANOVA) and the Tukey test (to distinguish differences between averages of the samples, in pairs).

It was assumed in advance that the samples (groups) would be equivalent. Two-dimensional or bilateral tests were used to compare the data for the preoperative period (seven days before surgery, to use as a standard for the masseter), 7, 14 and 21 days after surgery: (H0 = $1-2=0)$. The statistical software GraphPad Prism (GraphPad Software, Inc., 1996), version 2.01, was used. A confidence level of $5 \%(=0.05)$ was adopted.

\section{RESULTS}

General electrical activity of the masseter: The overall mean record of electrical activity among the patients before surgery on the seventh preoperative day was $73.0 \mathrm{mV}$ for both sides, with significantly higher activity among the men. In terms of gender, there was no significant difference in the side operated on (i.e., right and left side was operated with the same frequency in both sexes). 
Electrical activity of the masseter muscle on the operated side: On the seventh postoperative day, the electrical activity of the masseter muscle on the operated side fell to $66.1 \mathrm{mV}$ on average, and was significantly higher among the men. However, on the $21^{\text {st }}$ day there was a recovery of electrical activity on the operated side.

General electrical activity of the contralateral masseter: The electrical activity of the masseter on the contralateral side, on the seventh postoperative day, fell to $69.8 \mathrm{mV}$ in the total sample, with a significant difference between the sexes. On the $14^{\text {th }}$ day, the record among the men fell slightly but the difference between the men and the women remained significant until the $21^{\text {st }}$ postoperative day.

Electrical activity of masseter among women.Among the women, there was no significant difference between the electrical activity on operated and contralateral sides (Fig. 1) on the $7^{\text {th }}, 14^{\text {th }}$ or the 21 st postoperative days $(\mathrm{p}>0.22$ by the paired $t$ test). Analysis of variance comparing each postoperative electromyographic evaluation in the operated side with the preoperative period shows that the activity increased significantly in the 21 st day (Tukey test), compared with the $7^{\text {th }}$ and $14^{\text {th }}$ days $(\mathrm{p}=0.00)($ Fig. 2).

Electrical activity of the masseter among the men: Neither was there any difference between the sides among the men, in the comparison between the seventh day after surgery and the preoperative period $(p=0.82)$, but on the seventh day, the comparison between the sides showed a lower electromyographic record $(\mathrm{p}=0.02)$ on the operated side, a difference that was still significant on the $14^{\text {th }}$ day $(\mathrm{p}=0.02)$ and on the $21^{\text {st }}$ day $(\mathrm{p}=$ 0.049). On the contralateral side, among the women, analysis of variance revealed a difference indicating a recovery of the electrical signal on the 21 st day compared to the $7^{\text {th }}$ day, but with no difference in the intervening period (Fig. 1).

Analysis of variance on the operated side, among the men, showed a significant difference between the $21^{\text {st }}$ day and the $7^{\text {th }}$ day, revealing a gradual recovery of masseter activity (Fig. 3). It was noted that extraction of the third molar had no interference on the contralateral side in the men, with minimal signal loss on the $7^{\text {th }}$ day and a slight recovery in subsequent periods (Fig. 4).

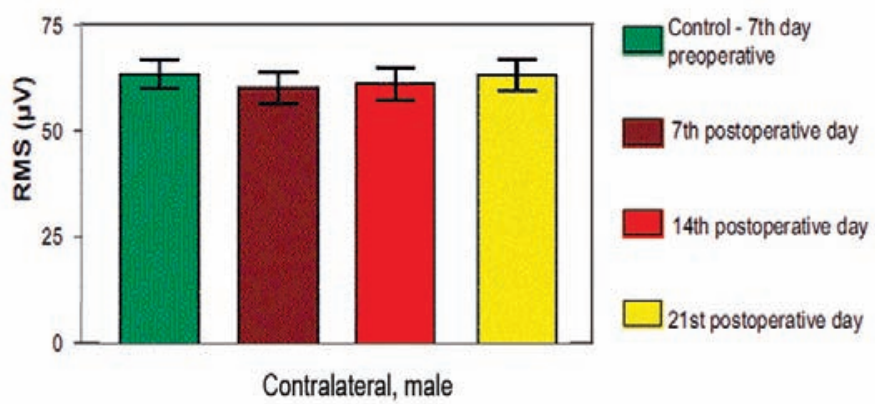

Fig. 1. Recordings of electrical activity $(\mathrm{mV})$ of the masseter muscle of the contralateral side between the women according to preoperative evaluation and between the $7^{\text {th }}$ and the $14^{\text {th }}$ and $21^{\text {st }}$ postoperative days. Analysis of variance.

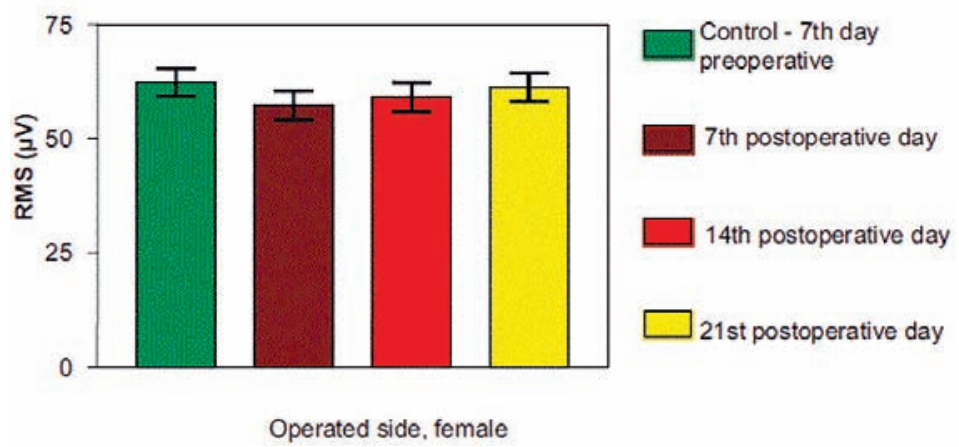

Fig. 2. Recordings of electrical activity $(\mathrm{mV})$ of the masseter muscle of the operated side in women, according to the preoperative evaluation between the $7^{\text {th }}$ and the $14^{\text {th }}$ and $21^{\text {st }}$ postoperative day. Analysis of variance (Tukey test).

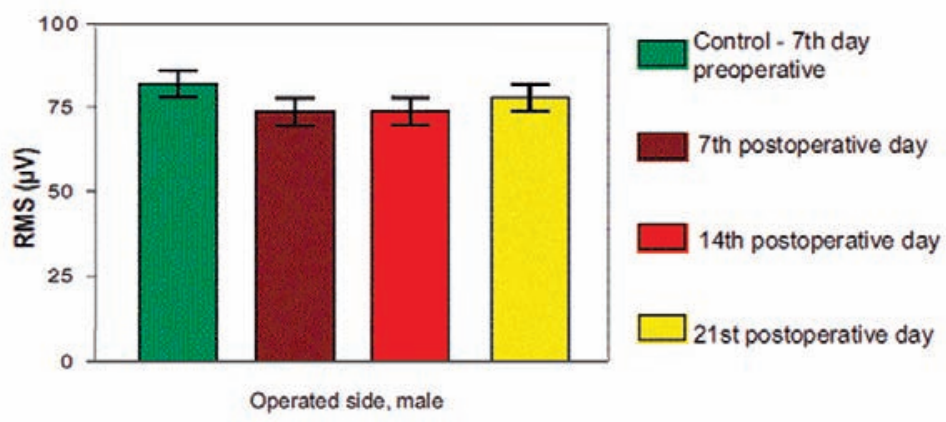

Fig. 3. Recordings of electrical activity $(\mathrm{mV})$ of the masseter muscle on the operated side among men, according to the preoperative evaluation and between the $7^{\text {th }}$ and the $14^{\text {th }}$ and $21^{\text {st }}$ postoperative day.

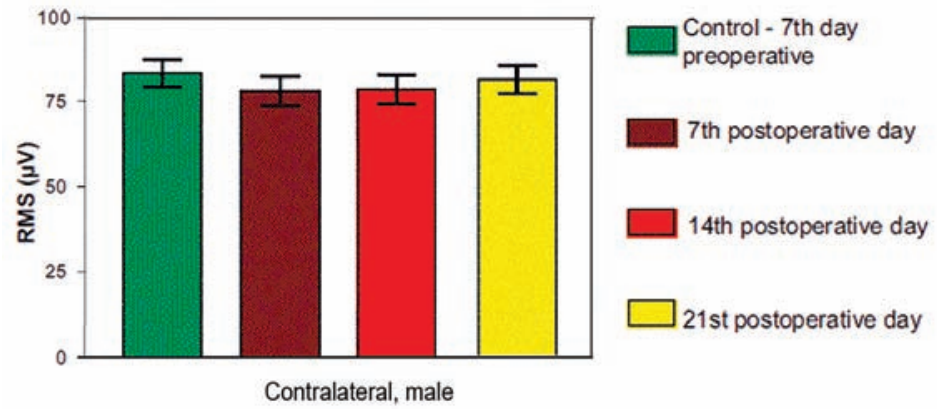

Fig. 4. Recordings of electrical activity $(\mathrm{mV})$ of the masseter muscle among men, on the side contralateral to the operated, according to the preoperative evaluation and between the $7^{\text {th }}$ and the $14^{\text {th }}$ and $21^{\text {st }}$ postoperative day. 


\section{DISCUSSION}

It is clear that even when properly indicated, extraction of third molars can result in a series of complications. There is a unanimity among authors as to the most frequent of these: trismus, swelling and pain, causing difficulty and limitation of mandibular movements (Berge, 1996; Mercier \& Precious; Garcia-Garcia et al.; Norholt et al.). It is evident to the surgeon that there is some loss of quality of life among patients due to these symptoms, since they cause difficulty performing basic mandibular movements, mastication and phonation.

Some symptoms, such as pain and swelling, are always present after third molar tooth extractions, regardless of the surgical technique used. These vary only in intensity, and can turn into serious complications such as nerve palsy (Chiapasco et al.; Brann et al.). Muscle complications in the postoperative period after third molar extraction normally occur in the masticatory muscles, which are innervated by the trigeminal nerve and are directly responsible for opening and closing the mouth, including the masseter (Stolov, 1990; Mannion \& Dolan, 1996). Trismus, or inability to open the mouth, is usually attributed to muscle spasms and occurs even in more simple procedures, due to impairment of the masseter and temporal muscle function (Garcia-Garcia $e t$ $a l$; ; Norholt et al.). The involvement of the muscular system can lead to a $15 \%$ to $20 \%$ decrease in mouth opening ability (Norholt et al.). Postoperative complications are clinically and functionally characterized. An anatomical knowledge of the region by the surgeon is also required, to determine the degree of muscular impairment (Suarez-Cunqueiro et al.).

Correct diagnosis of muscle function abnormalities has been attempted in several ways, taking into account the patient's history and the clinical examination methods used. Digital palpation of the muscle is of great value, but it is difficult to quantify the optimum pressure that needs to be exerted without using an algometer (Mohl, 1993; Bendtsen et al., 1995). Researchers have discussed the need for palpation examinations of the masticatory muscle, but they emphasize that sensitivity is essential. They advocate the importance of developing training programs for examiners, yet studies still show differences and doubts as to the parameters to be used as standards (Dahlström; Gray et al., 1994; Hermens et al., 2000; Conti et al., 2002).

However, technological development has brought other diagnostic tools, such as electromyography. The use of electromyography to study craniomandibular disorders has been extensively discussed in the literature in specific areas, such as physiotherapy, orthodontics and temporomandibular disorders, with satisfactory results, thereby justifying its use as a tool for pre and postoperative assessment of muscle function (Moss \& Willmont, 1984; Robledo-Fernández, 1987; Dahlström). The masseter is the most important muscle in mandibular movements. The decrease in electromyographic signal observed in this study is an indirect sign of masseter impairment. This impairment was found when comparing the signal before surgery with signals in the post-operative periods, demonstrating that some time is needed for normality to be restored. In our study, electromyography enabled the loss of function and recovery period to be monitored, as several measurements were taken over time.

The electrodes can be inserted or placed on the surface, and these are also known as skin electrodes, and are painless, non-invasive, and provide easy and quick access to the muscle (Duchêne \& Goubel, 1993). Bipolar surface electrodes are preferred due to their characteristics and conditions of use. In our work, we also opted for surface electrodes. While other authors suggest that the reference electrode should be placed on the wrist, in order to reduce noise during acquisition (Hermens et al.), we chose to use dual electrodes of the pediatric type, with a fixed distance between the poles $(20 \mathrm{~mm})$, which with no doubt facilitated their positioning. Patient positioning and preparation for placement of the electrodes were maintained, reducing impedance and ensuring good signal capture.

It is necessary to amplify the electromiographic signal, but without interfering with its features. Interference can come from the electrical power supply, making it necessary to use filters. The filters separate and restore the signal, and the recommendations for the analog filters are low-pass, $500 \mathrm{~Hz}$, and high-pass, 10 to $20 \mathrm{~Hz}$ (Hermens et al.; Robertson et al., 2004; Konrad, 2005). In our study, we chose to use bandpass filters set between $20 \mathrm{~Hz}$ and $300 \mathrm{~Hz}$. Care was taken to reduce possible interference, such as the use of an isolated, audiometric booth, without the presence of light, and a battery-run computer system. The purpose of these measures is to prevent direct or indirect participation of electricity, generating more secure and reliable data and obviating the need to use several filters.

Clinically, it was evident that a decrease in electrical activity of the masseter occurs in the period after surgery, and that recovery, contrary to our initial expectations, does not occur between 7 and 14 days after surgery, as was supposed based on the clinical experience. Our results 
showed a different situation: surface electromyography evidenced recovery only at around 21 to 28 days after surgery, and even later among the men. There are no studies in the literature using electromyography specifically in the extraction of third molars, and our preoperative and postoperative data may serve as reference for future studies, including the control for other variables such as pain scores.

In our study we can conclude that: the surface electromyography is an appropriate method for evaluating the masseter muscle activity after third molar extraction surgery; in the first seven days after mandibular third molar extraction, there is a $10 \%$ impairment in masseter activity compared with preoperative electric activity, with greater damage on the operated side; after 14 days, the recovery is greater on the operated side, with the two sides equalizing over time; the time needed for complete muscle recovery is about 21 days after surgery in women; in males, 21 days were not sufficient to restore the same level of muscle activity that was seen preoperatively.

BARROS, T. E. P.; CAMPOLONGO, G. D.; OLIVEIRA, N.; ALVES, N. \& OLIVEIRA, R. J. Estudio electromiográfico del músculo masétero tras cirugía del tercer molar inferior. Int. J. Morphol., 29(1):304-309, 2011.

RESUMEN: La cirugía de extracción del tercer molar es uno de los procedimientos realizados con mayor frecuencia en las áreas de traumatología y cirugía buco-maxilofacial. La evolución post-quirúrgica fue evaluada sobre la base de la evidencia clínica obtenida hasta el momento. El objetivo de este estudio fue analizar la evolución clínica post-operatoria del músculo masetero por medio de electromiografía de superficie, para evaluar la actividad muscular. Fueron realizados cuatro análisis: uno previo a la cirugía, para registrar la actividad normal, y tres en la post-quirúrgica: en el día del 7, 14 y 21 postoperatorio, en una muestra de 30 pacientes. El día 21 , hubo recuperación cercana a la normal de la señal eléctrica del músculo masetero en las mujeres, pero en los hombres esta actividad no alcanzó los niveles normales. La electromiografía de superficie es una herramienta segura y fiable para el control de la evolución postquirúrgica de la función del músculo masetero.

PALABRAS CLAVE: Electromiografía; Músculo masetero; Tercer molar; Electrodos.

\section{REFERENCES}

Bendtsen, L.; Jensen, R.; Jensen, N. K. \& Olesen, J. Pressurecontrolled palpation: a new technique which increases the reliability of manual palpation. Cephalalgia, 15(3):205-10, 1995.

Berge, T. I. Complications requiring hospitalization after third-molar surgery. Acta Odontol. Scand., 54(1):24-8, 1996.

Brann, C. R.; Brickley, M. R. \& Shepherd, J. P. Factors influencing nerve damage during lower third molar surgery. Br. Dent. J., 186(10):514-6, 1999.

Cerqueira, P. R.; Vasconcelos, B. C. \& Bessa-Nogueira, R. V. Comparative study of the effect of a tube drain in impacted lower third molar surgery. J. Oral Maxillofac. Surg., 62(1):57-61, 2004.

Chiapasco, M.; De Cicco, L. \& Marrone, G. Side effects and complications associated with third molar surgery. Oral Surg. Oral Med. Oral Pathol., 76(4):412-20, 1993.

Conti, P. C.; dos Santos, C. N. \& Lauris, J. R. Interexaminer agreement for muscle palpation procedures: the efficacy of a calibration program. Cranio, 20(4):289-94, 2002.
Dahlström, L. Electromyographic studies of craniomandibular disorders: a review of the literature. J. Oral Rehabil., 16(1):1-20, 1989.

Duchêne, J. \& Goubel, F. Surface electromyogram during voluntary contraction: processing tools and relation to physiological events. Crit. Rev. Biomed. Eng., 21(4):31397, 1993.

Garcia-Garcia, A.; Gude Sampedro, F.; Gandara Rey, J. \& Gallas Torreira, M. Trismus and pain after removal of impacted lower third molars. J. Oral Maxillofac. Surg., 55(11):1223-26, 1997.

Goldberg, M. H.; Nemarich, A. N. \& Marco, W. P. Complications after mandibular third molar surgery: a statistical analysis of 500 consecutive procedures in private practice. J. Am. Dent. Assoc., 111(2):277-9, 1985.

Goldstein, L. B. The use of surface electromyography in objective measurement of the muscle function in facial pain/temporomandibular dysfunction patients. Funct. Orthod., 17(3):26-9, 2000.

Gray, R. J.; Davies, S. J. \& Quayle, A. A. A clinical approach 
BARROS, T. E. P.; CAMPOLONGO, G. D.; OLIVEIRA, N.; ALVES, N. \& OLIVEIRA, R. J. Electromyographic study of the masseter muscle after lower third molar surgery. Int. J. Morphol., 29(1):304-309, 2011

to temporomandibular disorders. Examination of the articulatory system: the muscles. Br. Dent. J., 177(1):258, 1994.

Hermens, H. J.; Freriks, B.; Disselhorst-Klug, C. \& Rau, G. Development of recommendations for SEMG sensors and sensor placement procedures. J. Electromyogr. Kinesiol., 10(5):361-74, 2000.

Konrad, P. Signal origin and acquisition. In: The ABC of EMG. A practical introducion to kinesiological electromyography. Konrad, P. (Ed.). Boston, Noraxon EMG \& Sensor Systems, 2005.

Mannion, A. F. \& Dolan, P. Relationship between myoelectric and mechanical manifestations of fatigue in the quadriceps femoris muscle group. Eur. J. Appl. Physiol. Occup. Physiol., 74(5):411-9, 1996.

Mercier, P. \& Precious, D. Risk and benefits of removal of impacted third molars. A critical review of the literature. Int. J. Oral Maxillofac. Surg., 21(1):17-27, 1992.

Mohl, N. D. Reliability and validity of diagnostic modalities for temporomandibular disorders. Adv. Dent. Res., 7(2):113-9, 1993.

Moss, J. P. \& Willmont, D. R. A cephalometric and electromyographic investigation of patients treated for the correction of mandibular prognathism by mandibular surgery only. Br. J. Orthod., 11(2):59-68, 1984.

Norholt, S. E.; Aagaard, E.; Svensson, P. \& Sindet-Pedersen, $\mathrm{S}$. Evaluation of trismus, bite force, and pressure algometry after third molar surgery: a placebo controlled study of ibuprofen. J. Oral Maxillofac. Surg., 56(4):4207, 1998.

Robertson, D. G. E.; Caldwell, G. E.; Hamill, J.; Kamen, G. \& Whittlesey, S. N. Research methods in biomechanics. Champaign, Human Kinetics, 2004.

Robledo-Fernández, M. R. Estudio electromiográfico del músculo masetero. Rev. Cubana Estomatol., 24(3):291299, 1987.

Solberg, W. K. Temporomandibular disorders: physical tests in diagnosis. Br. Dent. J., 160(8):273-7, 1986.

Stolov, W. C. Eletrodiagnostic evaluation of acute and chronic pain. In: Bonica's management of pain. Stolov, W. C. 2nd Edition. Philadelphia, Lea and Febiger, 1990.
Suarez-Cunqueiro, M. M.; Gutwald, R.; Reichman, J.; Otero-Cepeda, X. L. \& Schmelzeisen R. Marginal flap versus paramarginal flap in impacted third molar surgery: a prospective study. Oral Surg. Oral Med. Oral Pathol. Oral Radiol. Endod., 95(4):403-8, 2003.

Correspondence to:

Tarley Eloy Pessoa de Barros

Institute of Orthopedics and Traumatology

Hospital das Clínicas

Faculdade de Medicina da Universidade de São Paulo

Rua Guarará 316

Jardim Paulista

São Paulo

BRAZIL

Email: tpbarros@uol.com.br

Received: 06-03-2010

Accepted: 24-11-2010 